\title{
E-Guidebook Automotive Tourism South West Java: Guide Special Riding Solo Pro-Environmental
}

\author{
Aylin Yumna Arief ${ }^{1}$, Alfi Syahreza ${ }^{2}$, Mochammad Refael Aldilama $P^{3}$ Eko Susanto $^{4}$ \\ Tourism Travel Business Study Program, Bandung State Polytechnic \\ Aylin.yumna.upw18@polban.ac.id
}

\begin{abstract}
Abstrack
This product is motivated by the growth of productive age in Indonesia which encourages the development of a dynamic and innovative lifestyle. Work pressure experienced by people of productive age has made the life cycle of this age segment more varied on weekends or on holidays. This phenomenon then led to the activity of motorbike riding (solo riding) from the city where you live to explore tourism destinations in inland areas. so that it can become an information center that can make it easier for people to visit a destination and something that is needed by every city, region that manages tourism activities. The development of technology, especially information, has made the tourism business grow. There are various terms used as an information center, one of which is Eguidebook. Besides having a function as a center for information about tourism to tourists who come, it can also be used as a tourism promotion tool. In the area of South West Java, there is still a lack of interest in tourists to visit this is due to a lack of information about routes, tourist attractions, accommodation and other supporting facilities. The making of this project aims to create an electronic design document for solo riding activities to the South West Java Region which prioritizes the principles of sustainable tourism, the design is carried out by searching for information in the South West Java Region types of tourist information needs, visual compilation, prototyping, user evaluation and finalizing the design. It is hoped that this project can be useful for those interested in solo riding and people who like to do automotive tourism
\end{abstract}

Keyword : special interest tourism, solo riding.

\begin{abstract}
Abstrak
Produk ini dilatar belakangi karena Pertumbuhan usia produktif di Indonesia mendorong perkembangan gaya hidup yang dinamis dan inovatif. Tekanan pekerjaan yang dialami masyarakat usia produktif membawa siklus hidup segmen usia ini menjadi lebih variatif di akhir pekan atau di hari liburnya. Fenomena ini kemudian memunculkan aktivitas berkendara motor (solo riding) dari kota tempat tinggal untuk mengeksplorasi destinasi pariwisata di daerah-daerah pedalaman. agar dapat menjadi pusat informasi yang dapat memudahkan masyarakat dalam mengunjungi sebuah destinasi dan suatu hal yang dibutuhkan oleh setiap kota, daerah yang mengelola aktivitas pariwisata. Perkembangan teknologi khususnya informasi membuat bisnis pariwisata semakin berkembang. Terdapat berbagai istilah yang digunakan sebagai pusat informasi salah satunya adalah $E$-guidebook. Selain memiliki fungsi sebagai pusat informasi mengenai pariwisata kepada wisatawan yang datang, juga dapat digunakan sebagai alat promosi pariwisata. Di Kawasan Jawa Barat Selatan masih kurang minat wisatawan untuk berkunjung hal ini dikarenakan kurangnya informasi mengenai jalur, obyek wisata, akomodasi dan sarana pendukung lainnya. Pembuatan proyek ini bertujuan untuk membuat dokumen perancangan elektronik bagi aktivitas berkendara sendiri (solo riding) ke Kawasan Jawa Barat Selatan yang mengutamakan prisip pariwisata berkelanjutan, Perancangan dilakukan dengan pencarian informasi Kawasan Jawa Barat Selatan jenis kebutuhan informasi wisatawan, penyusunan visual, Prototyping, evaluasi pengguna dan finalisasi rancangan. Diharapkan proyek ini dapat berguna bagi minat wisata khusus berkendara sendiri (solo riding) maupun masyarakat yang senang melakukan wisata otomotif
\end{abstract}

Kata kunci : wisata minat khusus, Solo riding.

\section{PENDAHULUAN}

Pertumbuhan usia produktif di Indonesia mendorong perkembangan gaya hidup yang dinamis dan inovatif. Tekanan pekerjaan yang dialami masyarakat usia produktif membawa siklus hidup segmen usia ini menjadi lebih variative di akhir pekan atau di hari liburnya. Fenomena ini kemudian memunculkan aktivitas berkendara motor (solo riding) dari kota tempat tinggal untuk mengeksplorasi destinasi pariwisata di daerah-daerah pedalaman. Berkendara sendiri (Solo Riding) merupakan kegiatan wisata minat khusus yang berorientasi pengalaman baru dan interaksi yang lebih era tantara pengendara dan destinasi. Wisata minat khusus tersebut bersesuaian dengan perkembangan pariwisata berkelanjutan (sustainable tourism). Wisata minat khusus 
(special interest tourism) merupakan pola wisata yang menekankan pada penghayatan dan penghargaan yang lebih terhadap kelestarian alam, lingkungan dan budaya ( Thalia, 2011) Salah satu destinasi pariwisata yang sesuai untuk kegiatan solo riding adalah kawasan Jawa Barat Selatan. Kawasan wisata minat khusus Jabar Selatan merupakan kawasan wisata yang terletak di sepanjang pantai dan jalur selatan Provinsi Jawa Barat yang didominasi oleh alam pantai, pertanian dan hutan. Membentang dari Kawasan Geopark CiletuhPalabuhanratu di sebelah Barat hingga Kawasan Wisata Pangandaran di sebelah Timur, secara aktual menjadi jalur wajib bagi peminat wisata minat khusus otomotif. Pembangunan jalan propinsi yang menghubungkan Sukabumi Selatan-Cianjur Selatan-Garut Selatan-Tasikmalaya Selatan hingga Kabupaten Pangandaran (BAPPEDA JABARPROV, 2017) menjadikan kawasan ini memiliki aksesibilitas yang baik sebagai prasyarat pengembangan wisata otomotif.

Kekayaan sumber daya alam yang dimiliki oleh Kawasan Jawa Barat Selatan dapat dijadikan sebagai kekuatan ekonomi untuk menutupi ketimpangan ekonomi Utara-Selatan Jawa Barat. Jika dibandingkan dengan Kawasan Utara Jawa Barat, kawasan di Selatan ini masih perlu dikembangkan dari sisi informasi khususnya mengenai jalur, daya tarik wisata, akomodasi dan sarana pendukung. Namun demikian, untuk menyelaraskan tujuan 2 pengembangan pariwisata dengan kelestarian alam, ekonomi dan sosial, maka perlu menerapkan konsep sustainable tourism. Hal ini sejalan dengan program United Nation World Tourism Organization (2017), dimana pengembangan pariwisata harus memperhatikan aspek keberlanjutan (sustainability), yaitu adanya keseimbangan antara ekonomi, sosial budaya, dan lingkungan (Widhiarni, 2019).

Untuk memecahkan masalah tersebut, dokumen ini menawarkan sebuah proyek perancangan panduan elektronik bagi aktivitas berkendara sendiri (solo riding) ke Kawasan Wisata Jawa Barat Selatan dengan mengutamakan prinsip pariwisata yang berkelanjutan.Buku panduan elektronik ini akan berisi mengenai informasi jalur wisata otomotif ke wilayah Jawa Barat Selatan meliputi obyek wisata, alternatif jalur yang sesuai dengan karakteristik solo riding, titik istirahat dan panduan mengenai interaksi dengan entitas sosial di destinasi wisata. Selain itu akan dicantumkan pula panduan keselamatan berkendara dan integrasi e-book dengan fitur Google Earth. Sehingga proposal ini menawarkan topik: E- Guidebook Wisata Otomotif Jawa Barat Selatan : Panduan Khusus Solo Riding Pro-Lingkungan.

Kawasan Wisata Jawa Barat Selatan saat ini masih belum mampu menandingi perkembangan Jawa Barat Tengah dan Utara, diindikasikan salah satunya akibat minimnya informasi mengenai daya tarik wisata di Kawasan Jawa Barat Selatan. Hal ini kontradiktif dengan fakta bahwa sumber daya alam dan budaya yang dimiliki di wilayah Jabar Selatan ini dapat diandalkan untuk meningkatkan keadaan ekonomi dan dapat menutupi ketimpangan antara Jawa Barat Utara-Selatan.

Proyek bertujuan untuk memberikan alternatif informasi berupa EGuidebook Wisata Otomotif bagi masyarakat untuk mengetahui lokasi daya tarik wisata, jalur, akomodasi dan sarana pendukung lainnya untuk mendorong kunjungan wisata ke wilayah ini sehingga dapat mengembangkan Kawasan wisata di Jabar Selatan. Proyek ini diharapkan dapat bermanfaat bagi seluruh stakeholder pariwisata yaitu, pemerintah swasta serta masyarakat untuk memperkaya sumber informasi wisata

\section{METODE}

Metode yang digunakan dalam program Karsa cipta ini adalah :

\section{Pengumpulan informasi}

Pengumpulan data dilakukan dengan mengumpulkan informasi melalui media sosial seperti jurnal, website, berita. Ini termasuk Teknik observasi dengan tidak langsung. Ditambah Wawancara dengan beberapa orang 
yang berpengalaman dalam kegiatan Solo Riding. Buku yang digunakan adalah buku yang berkaitan dengan fotografi, wisata, dan perancangan.

\section{Proyek rujukan}

Sebelum membuat perbandingan hal pertama yang perlu dilakukan adalah mencari produk yang akan dibuat. Dalam proyek ini digunakan contoh fisik dari handbook the Victorian rider dan perancangan buku panduan wisata pengendara sepeda motor di pulau Madura sebagai pembandingnya. Kemudian contoh tersebut bisa dijadikan sebagai gambaran atau referensi dalam pembuatan proyek yang dikerjakan.

\section{Sortasi data}

Data yang telah dikumpulkan lalu dipilah, dan dsederhanakan dimasukkan ke dalam luaran yang akan dicapai.

\section{Prototyping}

Setelah proses sortasi data, data dapat diolah dan dijadikan sebuah produk.

\section{Uji pasar}

uji pasar dilakukan dengan menyebarkan kuisioner beserta E-guidebook digital agar dapat diuji kelayakannya menurut pasar serta untuk memperoleh masukan dan saran dari masyarakat agar produk dapat diterbitkan lebih matang.

\section{Finalisasi}

Hasil Uji pasar akan dijadikan sebagai perbaikan pada produk yang akan finalisasi

\section{HASIL DAN PEMBAHASAN}

Hasil dari pembuatan E-guidebook wisata otomotif Kawasan Jawa Barat Selatan : panduan khusus solo riding pro-lingkungan. Yang didalamnya terdapat informasi mengenai jalur jalur, informasi obyek wisata, akomodasi dan sarana pendukung lainnya yang dapat ditempuh untuk mengeksplorasi wilayah Kawasan Jawa Barat Selatan untuk membantu memudahkan dalam memperoleh informasi.

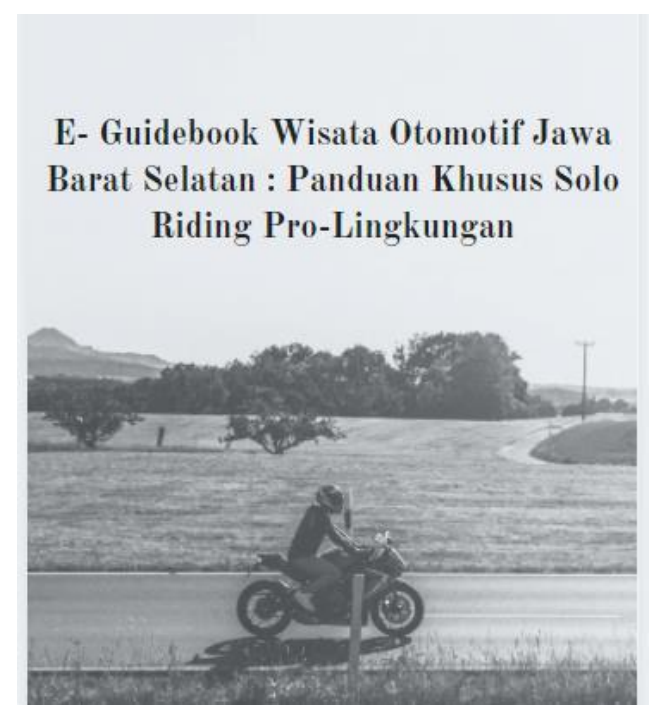

Gambar 1. Cover E-guidebook 
Aylin Yumna Arief, et al E-Guidebook Automotive Tourism South West Java: Guide Special Riding Solo ProEnvironmental

\section{Format dan Ukuran E-Guidebook}

E-guidebook wisata otomotif Jawa Barat Selatan : Panduan Khusus Solo Riding Pro-Lingkungan dibuat dengan spesifikasi berikut

Ukuran : 10 x $12 \mathrm{~cm}$

Halaman : 60

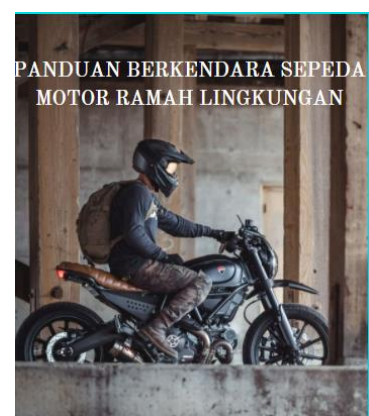

\section{Gambar 2. Panduan berkendara}

Pesan yang akan disajikan beruppa pendekatan yang singkat namun menjelaskan secara singkat dan padat mengenai informasi yang akan ditampilkan. Informasi yang disampaikan berupa :
a. Panduan berkendara sepeda motor ramah lingkungan
b. Jalur menuju kawasan wisata Jawa Barat Selatan
c. Akomodasi

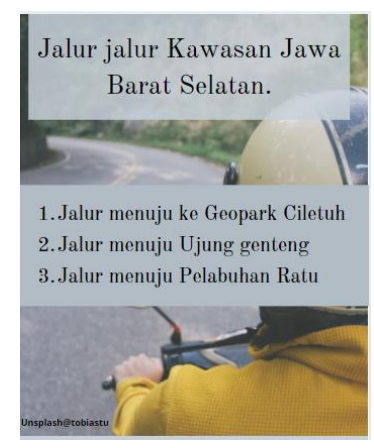

\section{Gambar 3. Jalur menuju kawasan Wisata}

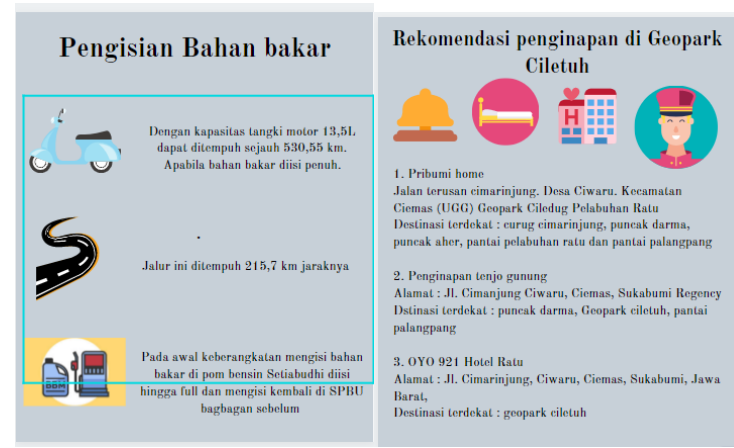

Gambar 4. Akomodasi 


\section{Teknik Visualisasi}

Di dalam E-Guidebook ini juga menampilkan peta jalur untuk mengakses lokasi tujuan wisata, serta daftar destinasi utama dan sekunder

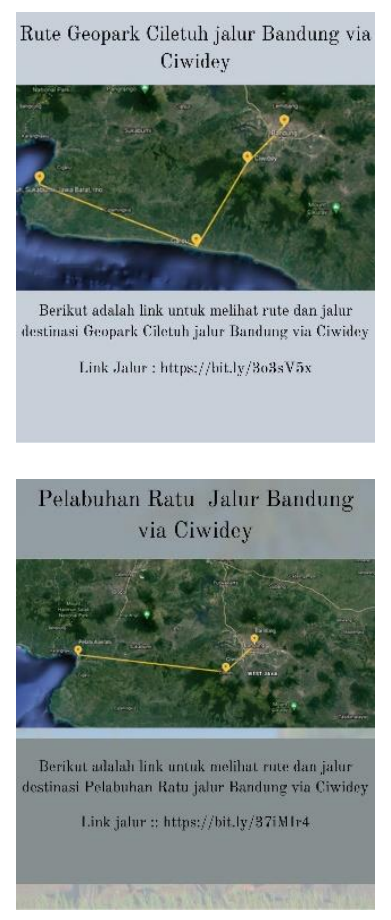

Gambar 5. Peta

\section{KESIMPULAN}

Daya tarik Kawasan wisata minat khusus Jabar Selatan merupakan Kawasan wisata pantai, laut dan hutan yang bersifat seperti petualangan seperti pantai ujung genteng, Geopark Ciletuh dan Pelabuhan Ratu. Dilihat dari perkembangan kawasannya, Kawasan Jabar Selatan ini termasuk dalam Kawasan yang relative belum berkembang seperti Kawasan wisata lainnya terkait dengan ketimpangan pembangunan wilayah di Jawa Barat. Wisata di Kawasan Jabar Selatan masih tertinggal apabia dibandingkan dengan Jawa Barat lainnya.

Potensi wisata di Kawasan Jawa Barat Selatan ini sangat baik karena banyak destinasi yang jarang terjamah oleh wisatawan hal ini disebabkan karena kurangnya informasi mengenai akses untuk menuju ke destinasi.

Pembuatan E-Guidebook wisata otomotif Jawa barat selatan : Panduan khusus Solo Riding Pro-Lingkungan, digunakan untuk menciptakan alternative informasi wisata berbasis teknologi yang dapat mengikuti perkembangan zaman, membantu wisatawan mendapatkan informasi dan membuat keputusan berwisata. Selain itu, pembuatan E-Guidebook dapat mempromosikan Kawasan wisata Jawa Barat Selatan. Dan diharapkan pembuatan E-guidebook dapat bermanfaat bagi para stakeholders seperti pemerintahan, masyarakat maupun wisatawan.

\section{UCAPAN TERIMA KASIH}

Penyusun mengucapkan terimakasih kepada program kreativitas mahasiswa Politeknik Negeri Bandung yang telah memberi dukungan terhadap mahasiswa pada tahun 2020. Ucapan terimakasih saya ucapkan untuk dosen pembimbing yang senantiasa selalu memberikan dukungan dan waktunya untuk membimbing dalam 
pengerjaan proposal, laporan kemajuan hingga laporan akhir. Penulis juga mengucapkan banyak terimakasih untuk semua pihak yang belum tercantum yang turut membantu dan memotivasi terselesaikannya penelitian ini.

\section{DAFTAR PUSTAKA}

(UNWTO), U. N. (2017). Kode etik pariwisata.

amorphouz. (2015). single riding, single rider.

BAPPEDA. (2017). Badan Perencanaan pembangunan daerah Provinsi Jawa Barat. Jawa Barat.

Ersanta, A. P. (2018). TRAVEL GUIDEBOOK HANG AROUND DESTINASI PADANG.

Ni Made Ayu Natih Widhiarni, P. E. (2019). Arsitektur Tradisional Bali Pada Bangunan Puri Sebagai Daya Tarik Wisata Minat Khusus Dalam Mendukung Pengembangan Pariwisata. Journal Tourism, Hospitality, Travel and Bussines Event , 46-52.

Oktavianus Sena Atmadja, D. H. (2015). PERANCANGAN BUKU DIGITAL PANDUAN PERJALANAN WISATA SEPEDA MOTOR DI PULAU MADURA. Jurnal DKV Adiwarna, Universitas kristen Petra.

Thalia. (2011). Pengembangan WIsata Buday Berbasis Wisata Ziarah. 